\title{
Does the etiology of infertility have any effect on perinatal outcomes?
}

\author{
Songül Alemdaroğlu (D), Gülşen Doğan Durdağ ${ }^{1}$ (D) , Şafak Yılmaz Baran ${ }^{1}$ (iD), Tayfun Çok ${ }^{1}$ (D) , \\ Erhan Şimşek $^{1}$ iD, Esra Bulgan Kılıçdağ ${ }^{1}$ (iD), Ebru Tarım² \\ ${ }^{1}$ Department of Obstetrics \& Gynecology, Başkent University School of Medicine Adana Dr. Turgut Noyan Teaching and Medical Research Center, Adana, Turkey \\ ${ }^{2}$ Ebru Tarm Obstetrics and Gynecology Clinic, Adana, Turkey
}

\begin{abstract}
Objective: Pregnancies after in vitro fertilization (IVF) are associated with a less favorable outcome compared to natural conception as consistently shown in various studies. However, etiologic factors behind this issue remain to be elucidated. We aimed to demonstrate whether the etiology of infertility has a role on poor pregnancy outcomes in IVF pregnancies.

Methods: In this retrospective case control study; IVF and spontaneous singleton pregnancies were investigated. The infertile patients were divided into six groups according to the etiology of their infertility (anovulation, male factor, tubal factor, endometriosis, unexplained infertility and poor ovarian reserve). The incidence of preeclampsia, gestational diabetes mellitus, intrahepatic cholestasis of pregnancy, preterm birth and birth weight discrepancies was examined between the groups and subgroups. After adjusting the confounding variables for each infertility subgroup such as demographic data, embryo stage in transfer (blastocyst against cleavage stage) and fresh and frozen embryo transfer status, the effect on pregnancy outcomes was investigated using multinomial logistic regression analysis. Results: The study included 934 patients in the IVF group and 1009 patients in the control group. While adverse pregnancy outcomes were more frequent in the general infertility group in comparison to the control group, after elimination of the confounding variables, the direct effect of the etiology of infertility on these outcomes could not be shown.

Conclusion: In the IVF pregnancies, most of the increased risk of poor pregnancy outcomes appeared to be explained by maternal characteristics (such as age, body mass index) and by treatment protocols rather than infertility etiology. Physicians should consider these risks while counselling patients.
\end{abstract}

Keywords: IVF pregnancies, infertility etiology, pregnancy outcomes, singletons.

\begin{abstract}
Özet: İnfertilite etiyolojisinin perinatal sonuçlar üzerinde bir etkisi var mıdır?

Amaç: İn vitro fertilizasyon (IVF) sonrası gebelikler, çeşitli çalışmalarda tutarlı şekilde gösterildiği üzere doğal konsepsiyona k1yasla daha az olumlu sonuç ile ilişkilidir. Ancak bu sorunun ardındaki etiyolojik faktörler henüz açıklanamamıştır. Çalışmamızda, infertilite etiyolojisinin IVF gebeliklerdeki kötü gebelik sonuçları üzerinde bir rolü olup olmadığını göstermeyi amaçladık.

Yöntem: Bu retrospektif olgu kontrol çalışmasında IVF ve spontane tekil gebelikler incelendi. İnfertil hastalar, infertilite etiyolojisine göre altı gruba ayrıldı (anovülasyon, erkek faktörü, tubal faktör, endometriyoz, açıklanamayan infertilite ve düşük over rezervi). Preeklampsi, gestasyonel diabetes mellitus, gebeliğin intrahepatik kolestazı, preterm doğum ve doğum ağırlığı uyuşmazlıklarının insidansı gruplar ve alt gruplar arasında incelendi. Her infertilite alt grubu için demografik veriler, transferde embriyo aşaması (blastokiste karşı klevaj aşaması) ve taze dondurulmuş embriyo transfer durumu gibi karışıklığa neden olan değişkenler düzeltildikten sonra, multinomiyal lojistik regresyon analizi kullanılarak gebelik sonuçları üzerindeki etki araştırıldı.

Bulgular: Çalışmaya IVF grubunda 934 hasta ve kontrol grubunda 1009 hasta dahil edildi. Advers gebelik sonuçları kontrol grubuna kıyasla genel infertilite grubunda daha sıkken, karıştırıcı değişkenlerin çıkarılması sonrasında infertilite etiyolojisinin bu sonuçlar üzerindeki doğrudan etkisi gösterilememiştir.

Sonuç: IVF gebeliklerde, artmış kötü gebelik sonucu risklerinin çoğunun maternal özelliklerle (örneğin yaş ve vücut kitle indeksi) ve infertilite etiyolojisinden ziyade tedavi protokolleriyle açıklanabildiği görülmektedir. Hekimler hastalara danışmanlık verirken bu riskleri dikkate almalıdır.
\end{abstract}

Anahtar sözcükler: IVF gebelikler, infertilite etiyolojisi, gebelik sonuçlar, tekil.

Correspondence: Ebru Tarım, MD. Ebru Tarım Obstetrics and Gynecology Clinic, Adana, Turkey.

e-mail: eatarim@hotmail.com / Received: January 24, 2021; Accepted: February 21, 2021

How to cite this article: Alemdaroğlu S, Doğan Durdağ G, Yılmaz Baran Ş, Çok T, Şimşek E, Bulgan Kılıçdă̆ E, Tarım E. Does the etiology of infertility have any effect on perinatal outcomes? Perinatal Journal 2021;29(2):98-105. doi:10.2399/prn.21.0292001 


\section{Introduction}

As expected, the number of patients receiving in vitro fertilization (IVF) treatment increased significantly over the years between 1997 and 2016 (5.3-fold in Europe, 4.6-fold in the USA and 3.0-fold in Australia and New Zealand). ${ }^{[1]}$ Although IVF is shown as a safe method, population-based studies denote unfavorable pregnancy outcomes in IVF pregnancies (in comparison to women with indicators of subfertility but without assisted reproductive technologies and fertile women with singleton pregnancies) such as preeclampsia, small for gestational age (SGA), low birth weight, congenital anomaly and gestational diabetes mellitus (GDM) ${ }^{[2,3]}$ The mechanisms of adverse pregnancy outcomes are uncertain. Advanced maternal age, ${ }^{[4]}$ increased body mass index, ${ }^{[5]}$ underlying infertility etiology ${ }^{[6]}$ treatment protocols, ${ }^{[7]}$ fresh or frozen transfer of embryo ${ }^{[8]}$ and the day of embryo transfer ${ }^{[0]}$ are considered to be among etiological reasons for adverse pregnancy outcomes. The effect of infertility on pregnancy outcomes is indisputable, but the results among infertility etiologies are still not clear.

We aimed to analyze and compare the pregnancy outcomes of IVF and spontaneous conceptions, based on infertility etiologies which included anovulation, endometriosis, tubal factor, poor ovarian reserve, unexplained infertility and male factor. The analyzed adverse pregnancy outcomes were preterm delivery (PTD) $(<34$ weeks; $<37$ weeks), preeclampsia, GDM and intrahepatic cholestasis of pregnancy (ICP).

\section{Methods}

This study is a retrospective case control study, which included couples who were not able to achieve pregnancy by unprotected sexual intercourse for at least 6 months after the age of 35 and at least 1 year before the age of 35. A retrospective analysis of 990 consecutive IVF patients who visited the infertility clinic at our university hospital between January 2003 and December 2011 was performed. The infertile couples were classified under six subgroups according to the etiology of their infertility: (1) tubal factor: no observation of tubal transition in hysterosalpingography (partial or complete, uni-bilateral); (2) anovulation: defined by the modified Rotterdam criteria; ${ }^{[10]}$ (3) male factor: 2 or more abnormal semen analysis findings according to the World
Health Organization (WHO) criteria; ${ }^{[1]]}$ (4) unexplained infertility: normal semen analysis, normal tubal transition in hysterosalpingography (HSG), normal ovarian reserve (normal regular menstrual cycle in addition to 4 or more antral follicles in at least 1 ovary) according to the WHO criteria; ${ }^{[12]}(5)$ poor ovarian reserve (POR): defined by the Bologna criteria; ${ }^{[13]}$ (6) endometriosis: observation of endometrioma in ovaries in transvaginal ultrasonography during pelvic examination, detection of endometriosis findings in the patient with chronic pelvic pain or demonstration of the presence of endometriosis in laparoscopic examination.

The fresh-frozen embryo transfer status and 3rd-5th day transfer status of these patients were examined from the system records. Since only ICSI was applied at the clinic where the study was carried out, all IVF pregnancies were evaluated in one technique group.

For the control group, the files and records of singleton pregnancies were randomly (with a double-digit file number from the most recent to the most distant date) selected from 10,548 patients whose entire antenatal follow ups and births took place at our center in the same period. In order to prevent selection bias, we have taken time interval instead of matched controls. Confounding factors were aimed to be eliminated by large number of cases presented in the control group.

All multiple pregnancies (including vanishing twins), patients with chronic diseases such as chronic hypertension, chronic renal diseases, diabetes mellitus and chronic inflammatory diseases and those with poor obstetric history such as recurrent pregnancy loss, preterm birth and preeclampsia, oocyte donation pregnancies were excluded from the control and IVF groups. Patients with 2 or more reported infertility etiologies were excluded from the IVF group.

For all patients in the IVF and control groups, mother's age, body mass index at the onset of pregnancy $\left(\mathrm{kg} / \mathrm{m}^{2}\right)$, smoking status, week of pregnancy at birth (calculated based on the first day of the last menstrual cycle) and birth weight (grams) of the baby were assessed.

Pregnancy outcomes included PTD (all deliveries under 37 weeks; patients under 34 weeks were evaluated as a separate group), ICP (diffuse body pruritus and increased serum bile acids), SGA (fetus with birth weight less than the 10th percentile for gestational age), preeclampsia (blood pressure levels $\geq 140 / 90 \mathrm{mmHg}$ on 
two measurements at least 6-h apart with proteinuria $\geq 0.3 \mathrm{~g} /$ day after 20 weeks of gestation) and GDM diagnosed according to the protocol of the American Diabetic Association. ${ }^{[14]}$

Firstly, the patient characteristics and pregnancy outcomes of the spontaneous conception group was compared to the entire infertility group. Afterwards, the subgroups were compared to the control group one by one. To investigate the direct effect of infertility etiology on pregnancy outcomes, the unadjusted odds ratio and adjusted odds ratio were calculated. While the unadjusted odds ratio questioned the direct effect of infertility etiology on pregnancy outcomes, in the adjusted odds ratio, adjustment was made based on the mother's age, BMI, day of transfer and frozen-fresh embryo transfer status, and the sole risk ratio of infertility etiology for pregnancy outcomes was calculated. The unadjusted odds ratio and adjusted odds ratio were created by a multiple imputation model.

This study was approved by the Ethics Committee for Clinical Investigations of the University (project no: KA 12-212). The statistical analysis of the data were conducted using the IBM SPSS Statistics Version 20.0 (IBM Corp. released 2011. IBM SPSS Statistics for Windows, Version 20.0. Armonk, NY, USA) package software. The post hoc power analysis of the control group was conducted on the website www.clincalc.com with an alpha value of 0.05 . The categorical measurements are summarized as frequency and percentage, while the numerical ones are summarized as mean and standard deviation. If the continuous variables were normally distributed, they are described as mean \pm standard deviation, and if the continuous variables were not normally distributed, they are described as the median values. The normality tests were conducted using graphs such as histogram, P-P plot and Q-Q plot. The chisquared test statistics were used for the intergroup comparisons of the categorical measurements. Independentsamples t-test was used to compare the birth weight between the control and infertility groups. In the general comparison of the birth weight between the control and infertility groups, one-way analysis of variance (ANOVA) and post hoc Games-Howell test were used. In the calculation of the risk coefficients of various characteristics such as pregnancy complications for the infertility groups in comparison to the control group, multinomial logistic regression analysis was used. In all tests, the statistical significance level was taken as $\mathrm{p}<0.05$.

\section{Results}

Patients meeting all criteria, 1009 (51.9\%) in the control group and 934 (48.1\%) in the IVF group, were included in the study. 56 infertile patients who did not meet the criteria were excluded from the IVF group. The mean maternal age in the control group was $29.9 \pm 4.7$, while it was $30.9 \pm 4.8$ in the IVF group $(\mathrm{p}<0.001)$. The mean BMI values of the two groups were $25.2 \pm 3.9 \mathrm{~kg} / \mathrm{m}^{2}$ and $25.8 \pm 4.2 \mathrm{~kg} / \mathrm{m}^{2}$ ( $\left.\mathrm{p}=0.004\right)$, respectively (Table 1). When the control group and the IVF group (as a single group) were compared in terms of the pregnancy outcomes, the

Table 1. Comparison of the demographic characteristics, pregnancy outcomes and birth weight of control and IVF groups.

\begin{tabular}{|c|c|c|c|c|}
\hline & Control $(n=1009)$ & IVF $(n=934)$ & p-value & Post hoc power \\
\hline Maternal age* & $29.9 \pm 4.7$ & $30.9 \pm 4.8$ & $<0.001$ & \%99.6 \\
\hline $\mathrm{BMI}^{*}$ & $25.2 \pm 3.9$ & $25.8 \pm 4.2$ & 0.004 & $\% 90.2$ \\
\hline Smoking- n (\%) & $5 \%$ & $5.2 \%$ & 0.903 & - \\
\hline GDM & $68(7 \%)$ & $223(24 \%)$ & $<0.001$ & $\% 100$ \\
\hline Preeclampsia & $23(2 \%)$ & $61(7 \%)$ & $<0.001$ & $\% 100$ \\
\hline SGA & $54(5 \%)$ & $80(9 \%)$ & 0.005 & $\% 93.3$ \\
\hline ICP & $11(1.1 \%)$ & $8(0.9 \%)$ & 0.601 & - \\
\hline Preterm $<34$ & $25(3 \%)$ & $46(5 \%)$ & 0.004 & $\% 61.6$ \\
\hline Preterm<37 & $93(9 \%)$ & $163(18 \%)$ & $<0.001$ & $\% 100$ \\
\hline Birth weight & $3278 \pm 536$ & $3115 \pm 602$ & $<0.001$ & $\% 100$ \\
\hline
\end{tabular}

*Mean \pm SD. 
IVF group was found to have higher rates of GDM (control vs IVF, $7 \%$ vs $24 \%, \mathrm{p}<0.001$ ), preeclampsia (control vs IVF, $2 \%$ vs $7 \%$; p $<0.001$ ), SGA (control vs IVF; $5 \%$ vs $9 \%, \mathrm{p}=0.005)$ and PTD ( $<37$ weeks; control vs IVF, $9 \%$ vs $18 \%$; $\mathrm{p}<0.001,<34$ weeks; control vs IVF, $3 \%$ vs $5 \%, \mathrm{p}=0.004)$ than the control group. The weights of the newborns of the women in the IVF group were lower in comparison to the control group (control vs IVF, $3278 \pm 536$ vs $3115 \pm 602, \mathrm{p}<0.001)$. There was no significant difference between the control and IVF group in terms of the ICP rates $(\mathrm{p}=0.602)$ (Table 1). The post hoc power analysis results are presented in Table 1.

Distribution of the 934 patients in the IVF group into the subgroups was as follows: unexplained infertility: $\mathrm{n}=278(29.8 \%)$, endometriosis: $\mathrm{n}=20(2.1 \%)$, POR: $\mathrm{n}=48(4.8 \%)$, male factor: $\mathrm{n}=428(45.8 \%)$, tubal factor: $\mathrm{n}=75(8 \%)$, and anovulation: $\mathrm{n}=85$ (9.1\%). The demographic data of the subgroups including maternal age, BMI and smoking status are shown in Table 2. While the maternal age was the highest in the POR group $(35.9 \pm 4.5, \mathrm{p}<0.001)$, the highest $\mathrm{BMI}$ value was in the anovulation group $\left(27.6 \pm 4.8 \mathrm{~kg} / \mathrm{m}^{2}, \mathrm{p}<0.001\right)$. Smoking status was similar among all subgroups.

The incidences of GDM and preeclampsia were found to be significantly higher when the IVF subgroups were compared to the control group one by one $(\mathrm{p}<0.001)$. There was no significant difference between the control group and all subgroups of IVF in terms of the SGA and ICP rates (Table 2). There was no significant difference among the subgroups in terms of PTD under 34 weeks. However, there was a significant difference in the anovulation and tubal factor groups in comparison to the control group in terms of PTD under 37 weeks (Table 2). The birth weight was significantly lower in the male factor and anovulation groups than the control group $(p<0.001)$, while there was no significant difference between the other subgroups and the control group (Table 2).

Regarding the unadjusted odds ratio, which questioned the effects of infertility etiology on pregnancy outcomes, an increased risk was detected in the anovulation subgroup only in terms of preeclampsia (OR: 2.38 [1.19-4.76]). The data were further analyzed after the regression of significant confounding factors such as mother's age, BMI, day of transfer and frozen-fresh embryo transfer status (adjusted odds ratio). There was a significant difference in the male factor group (OR: 1.48 [1.05-2.07]). No additional effects of the subgroups on pregnancy outcomes were observed in the unadjusted odds ratio or the adjusted odds ratio (Table 3 ).

\section{Discussion}

In this study, we categorized IVF patients into six subgroups to investigate the effects of different infertility etiologies on pregnancy outcomes of IVF pregnancies. After adjusted with mother's age, BMI, day of transfer

Table 2. Comparison of the demographic characteristics, pregnancy outcomes and birth weight of the control group and IVF subgroups.

\begin{tabular}{|c|c|c|c|c|c|c|c|c|}
\hline & \multirow[b]{2}{*}{$\begin{array}{l}\text { Control } \\
(n=1009)\end{array}$} & \multicolumn{6}{|c|}{ IVF group $(n=934)$} & \multirow[b]{2}{*}{ p-value } \\
\hline & & $\begin{array}{l}\text { Unexplained } \\
\qquad(n=278)\end{array}$ & $\begin{array}{l}\text { Endometriosis } \\
\qquad(n=20)\end{array}$ & $\begin{array}{c}\text { POR } \\
(n=48)\end{array}$ & $\begin{array}{l}\text { Male factor } \\
\qquad(n=428)\end{array}$ & $\begin{array}{l}\text { Tubal factor } \\
\qquad(n=75)\end{array}$ & $\begin{array}{l}\text { Anovulation } \\
\quad(n=85)\end{array}$ & \\
\hline Maternal age* & $29.9 \pm 4.7$ & $31.2 \pm 4.6$ & $31.6 \pm 3.8$ & $35.9 \pm 4.5$ & $30.2 \pm 4.8$ & $30.8 \pm 4.5$ & $30.5 \pm 4.3$ & $<0.001$ \\
\hline $\mathrm{BMI}^{*}$ & $25.3 \pm 4.0$ & $25.5 \pm 4.2$ & $25.5 \pm 4.1$ & $26.1 \pm 3.9$ & $25.6 \pm 4.2$ & $26.3 \pm 3.9$ & $27.6 \pm 4.8$ & $<0.001$ \\
\hline Smoking- n (\%) & $28(5 \%)$ & $22(8 \%)$ & NA & $3(7 \%)$ & $16(4 \%)$ & $2(3 \%)$ & $4(5 \%)$ & 0.144 \\
\hline GDM & $68(7 \%)$ & $59(21 \%)$ & $3(15 \%)$ & $17(35 \%)$ & $107(25 \%)$ & $20(27 \%)$ & $17(20 \%)$ & $<0.001$ \\
\hline Preeclampsia & $23(2 \%)$ & $22(8 \%)$ & NA & $2(4 \%)$ & $21(5 \%)$ & $5(7 \%)$ & $11(13 \%)$ & $<0.001$ \\
\hline SGA & $54(5 \%)$ & $22(8 \%)$ & $1(5 \%)$ & $2(4 \%)$ & $37(9 \%)$ & $10(13 \%)$ & $8(9 \%)$ & 0.053 \\
\hline ICP & $11(1 \%)$ & $4(2 \%)$ & NA & $1(2 \%)$ & $2(0.5 \%)$ & $1(1 \%)$ & NA & 0.589 \\
\hline Preterm<34 & $25(3 \%)$ & $11(4 \%)$ & $1(5 \%)$ & $1(2 \%)$ & $22(5 \%)$ & $5(7 \%)$ & $5(7 \%)$ & 0.083 \\
\hline Preterm<37 & $93(9 \%)$ & $38(14 \%)$ & $2(10 \%)$ & $9(19 \%)$ & $78(18 \%)$ & $16(21 \%)$ & $20(24 \%)$ & $<0.001$ \\
\hline Birth weight & $3278 \pm 536$ & $3140 \pm 572$ & $3285 \pm 470$ & $3152 \pm 591$ & $3092 \pm 595$ & $3114 \pm 722$ & $3087 \pm 660$ & $<0.001$ \\
\hline
\end{tabular}

*Mean \pm SD. 
and frozen-fresh embryo transfer status; the results of our study suggested that most of the increased pregnancy risk in infertile patients may be explained by maternal characteristics and the effects of assisted reproductive techniques rather than underlying conditions causing infertility.

Many etiological factors for adverse pregnancy outcomes have been investigated, but major etiological and pathological mechanisms which might cause unfavorable pregnancy outcomes have not been uncovered yet. ${ }^{[15]}$ In the anovulation group, the BMI was found to be a significant determinant of preeclampsia based on the unadjusted OR [95\% CI]: 2.38 [1.19-4.76], while this difference was absent in terms of the adjusted odds ratio. In the male factor group, the total effect on GDM in terms of the adjusted odds ratio was determined as modestly higher (95\% CI: 1.48 [1.05-2.07]), which was an unexpected result in our study. In the literature, Tobias et al. reported similar findings, and they suggested that more scans are made among couples experiencing infertility problems. ${ }^{[16]}$ Mechanisms that may disrupt the success of pregnancy such as inflammatory pathways, hormonal anomalies, decidual aging and vascular anomalies may contribute to these outcomes. ${ }^{[17]}$ Higher determination of the incidence of preeclampsia and GDM in all IVF subgroups in comparison to the control group suggested that hormonal/metabolic disorders may have a role in the etiology of all IVF pregnancies in accordance with the hypothesis of Vannuccini et al. ${ }^{[17]}$ Moreover, the association of increased BMI, maternal age and smoking with maternal and obstetric risks is known. ${ }^{[4,5,18]}$

Additionally, cleavage stage embryo (3rd day) and blastocyst (5th day) transfers result in different pregnancy outcomes. ${ }^{[9]}$ While the potential effects of the embryo culture are reduced by placing the cleavage stage embryo into the uterine cavity at its physiological time in 3rd-day transfer, 5th-day blastocyst transfer provides time for healthy embryo selection. The effects of fresh and frozen embryo transfer on pregnancy outcomes were investigated in the meta-analysis of Maheshwari et al. including 26 studies, and accordingly, PTD and low birth weight rates were lower in frozen embryo transfer, whereas higher rates of pregnancy-related hypertensive diseases were found. ${ }^{[8]}$ Different results are encountered in the literature based on adjusted etiological factors for various characteristics such as maternal features and treatment protocols.

In a study which compared unexplained infertility and the male factor, after adjusting for patients' age,

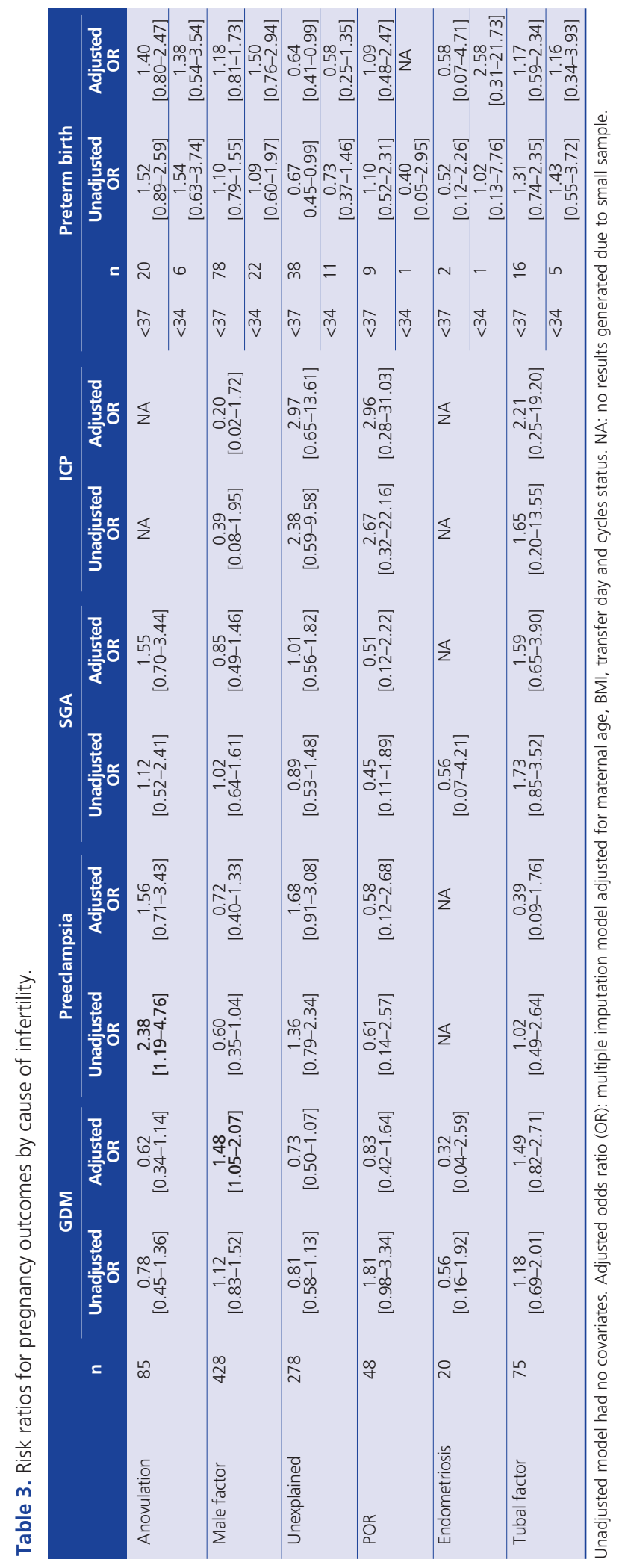


BMI and smoking status, there was no difference between the two groups in terms of GDM, preeclampsia or PTD ${ }^{[19]}$ In the study of Thomson et al., increased preeclampsia/eclampsia, abruptio placenta, placenta previa and low birth weight rates were determined in the infertile group including 4221 patients in comparison to the general population, and when the patients in the infertile group were examined based on their etiologies (anovulation (24\%), endometriosis (3\%), tubal problems $(12 \%)$, unexplained infertility $(19 \%)$ and male factor infertility (34\%), no difference was found in their obstetric and neonatal outcomes. ${ }^{[20]}$ Messerlian et al., who investigated the effects of 6 different infertility etiologies on PTD, found that uterine anomalies including myomas, adhesions and malformations were the only potential cause to be directly related to PTD risk, but the statistical significance of the result was on the limit. ${ }^{[21]}$ Among studies that investigated separate effects of infertility etiologies on pregnancy outcomes, Stern et al. evaluated 235,985 ART cycles in 145,660 infertile women, and as in our study, no difference was found regarding birth weights and pregnancy durations among patients with endometriosis, male factor infertility, low ovarian reserve, unexplained infertility and anovulation. ${ }^{[2]}$

Hayashi et al. compared ART techniques (ovulation stimulation medications $n=4111$; IUI $n=2351$ and IVFET $n=4570$ ) to spontaneous pregnancies, and higher rates of PTD and low birth weight were observed in infertile patients independently of the ART technique. ${ }^{[23]}$ Studies on sub-fertile women have shown that patients are exposed to pregnancy risks even without receiving any treatment. ${ }^{[24,25]}$ While such studies suggest that infertility-related maternal factors, rather than the ART procedures themselves, may contribute to negative outcomes, studies that report increased risk for poor pregnancy outcomes for an ART singleton in comparison to a non-ART sibling in sub-fertile singleton pregnancies demonstrate the effects of ART ${ }^{[2,27]}$ Likewise, pregnancies in surrogate mothers showed similar risk factors, and determination of shorter pregnancy duration $(38.8 \pm 2.1$ vs $39.7 \pm 1.4)$, higher rates of PTD $(10.7 \%$ vs $3.1 \%)$, GDM, preeclampsia and low birth weights $(7.8 \%$ vs $2.4 \%)$ demonstrated that infertility treatment may potentially affect pregnancy outcomes despite a healthy uterine environment. ${ }^{[28]}$

Too many confounding factors prevent drawing a strict conclusion on pregnancy outcomes in infertile patients. It could be only possible to understand poor obstetric outcomes after determining the pathological mechanisms of infertility. Although we studied the effects of infertility etiologies, there are many more factors related to the embryo and its implantation process. Studies proposing mechanisms on these factors have focused on changes in endometrial receptivity, genetic and epigenetic mechanisms of implantation, trophoblastic invasion and growth, in addition to the biological effects on the oocyte or embryo such as embryo culture media, PGD (preimplantation genetic diagnosis), cryopreservation technique and transfer day, as well as hormonal changes induced by ovarian hyperstimulation. ${ }^{[7,29-31]}$

This study included single referral IVF center patients. Strict inclusion criteria were applied, and a random control group was chosen. A major limitation of this study was its retrospective nature with inherent confounding variables affecting perinatal outcomes. The infertility etiology groups might not have contained a sufficient number of patients to detect small differences in pregnancy outcomes like ICP, and power analysis was conducted through post hoc analysis.

\section{Conclusion}

It is highly difficult to determine the specific etiology and scope of pregnancy risks in IVF pregnancies. Each cause and specific characteristic may play an independent and important role. With existing studies, it is not possible to completely explain the effects and place of maternal characteristics, infertility etiology and treatment protocols in pregnancy outcomes. Therefore, further epidemiological and basic research is needed.

Funding: This work did not receive any specific grant from funding agencies in the public, commercial, or not-for-profit sectors.

Compliance with Ethical Standards: The authors stated that the standards regarding research and publication ethics, the Personal Data Protection Law and the copyright regulations applicable to intellectual and artistic works are complied with and there is no conflict of interest.

\section{References}

1. De Geyter C, Wyns C, Calhaz-Jorge C, de Mouzon J, Ferraretti AP, Kupka M, et al. 20 years of the European IVFmonitoring Consortium registry: what have we learned? A comparison with registries from two other regions. Hum Reprod 2020;35:2832-49. [PubMed] [CrossRef]

2. Qin J-B, Sheng X-Q, Wu D, Gao S-Y, You Y-P, Yang T$\mathrm{B}$, et al., Worldwide prevalence of adverse pregnancy out- 
comes among singleton pregnancies after in vitro fertilization/intracytoplasmic sperm injection: a systematic review and meta-analysis. Arch Gynecol Obstet 2017;295:285-301. [PubMed] [CrossRef]

3. Qin J, Sheng X, Wu D, Gao S, You Y, Yang T, et al. Adverse obstetric outcomes associated with in vitro fertilization in singleton pregnancies: a prospective cohort study. Reprod Sci 2017;24:595-608. [PubMed] [CrossRef]

4. Pinheiro RL, Areia AL, Pinto AM, Donato H. Advanced maternal age: adverse outcomes of pregnancy, a meta-analysis. Acta Med Port 2019;32:219-26. [PubMed] [CrossRef]

5. Cheney K, Farber R, Barratt AL, McGeechan K, de Vries B, Ogle R, et al. Population attributable fractions of perinatal outcomes for nulliparous women associated with overweight and obesity, 1990-2014. Med J Aust 2018;208:119-25. [PubMed] [CrossRef]

6. Kawwass JF, Crawford S, Kissin DM, Session DR, Boulet S, Jamieson DJ. Tubal factor infertility and perinatal risk after assisted reproductive technology. Obstet Gynecol 2013;121: 1263-71. [PubMed] [CrossRef]

7. Kondapalli LA, Perales-Puchalt A. Low birth weight: is it related to assisted reproductive technology or underlying infertility? Fertil Steril 2013;99:303-10. [PubMed] [CrossRef]

8. Maheshwari A, Pandey S, Raja EA, Shetty A, Hamilton M, Bhattacharya S. Is frozen embryo transfer better for mothers and babies? Can cumulative meta-analysis provide a definitive answer? Hum Reprod Update 2018;24:35-58. [PubMed] [CrossRef]

9. Martins WP, Nastri CO, Rienzi L, van der Poel SZ, Gracia CR, Racowsky C. Obstetrical and perinatal outcomes following blastocyst transfer compared to cleavage transfer: a systematic review and meta-analysis. Hum Reprod 2016;31: 2561-9. [PubMed] [CrossRef]

10. Rotterdam ESHRE/ASRM-Sponsored PCOS Consensus Workshop Group. Revised 2003 consensus on diagnostic criteria and long-term health risks related to polycystic ovary syndrome. Fertil Steril 2004;81:19-25. [PubMed] [CrossRef]

11. World Health Organization. WHO laboratory manual for the examination and processing of human semen. 5th ed. Geneva: WHO; 2010.

12. Collins JA, van Steirteghem A. Overall prognosis with current treatment of infertility. Hum Reprod Update 2004;10:309-16. [PubMed] [CrossRef]

13. Ferraretti AP, La Marca A, Fauser BCJM, Tarlatzis B, Nargund G, Gianaroli L; ESHRE working group on Poor Ovarian Response Definition. ESHRE consensus on the definition of 'poor response' to ovarian stimulation for in vitro fertilization: the Bologna criteria. Hum Reprod 2011;26:1616-24. [PubMed] [CrossRef]

14. International Association of Diabetes and Pregnancy Study Groups Consensus Panel; Metzger BE, Gabbe SG, Persson B, Buchanan TA, Catalano PA, Damm P, et al. International Association of Diabetes and Pregnancy Study Groups recommendations on the diagnosis and classification of hyperglycemia in pregnancy. Diabetes Care 2010;33:676-82. [PubMed] [CrossRef]

15. Palomba S, Homburg R, Santagni S, La Sala GB, Orvieto R. Risk of adverse pregnancy and perinatal outcomes after high technology infertility treatment: a comprehensive systematic review. Reprod Biol Endocrinol 2016;14:76. [PubMed] [CrossRef]

16. Tobias DK, Gaskins AJ, Missmer SA, Hu FB, Manson JE, Buck Louis GM, et al. History of infertility and risk of type 2 diabetes mellitus: a prospective cohort study. Diabetologia 2015;58:707-15. [PubMed] [CrossRef]

17. Vannuccini S, Clifton VL, Fraser IS, Taylor HS, Critchley H, Giudice LC, et al., Infertility and reproductive disorders: impact of hormonal and inflammatory mechanisms on pregnancy outcome. Hum Reprod Update 2016;22:104-15. [PubMed] [CrossRef]

18. Inoue S, Naruse H, Yorifuji T, Kato T, Murakoshi T, Doi $\mathrm{H}$, et al. Impact of maternal and paternal smoking on birth outcomes. J Public Health (Oxf) 2017;39:1-10. [PubMed] [CrossRef]

19. Amouyal M, Boucekine M, Paulmyer-Lacroix O, Agostini A, Bretelle F, Courbiere B. No specific adverse pregnancy outcome in singleton pregnancies after assisted reproductive technology (ART) for unexplained infertility. J Gynecol Obstetrics Hum Reprod 2020;49:101623. [PubMed] [CrossRef]

20. Thomson F, Shanbhag S, Templeton A, Bhattacharya S. Obstetric outcome in women with subfertility. BJOG 2005;112:632-7. [PubMed] [CrossRef]

21. Messerlian C, Platt RW, Ata B, Tan S-L, Basso O. Do the causes of infertility play a direct role in the aetiology of preterm birth? Paediatr Perinat Epidemiol 2015;29:101-12. [PubMed] [CrossRef]

22. Stern JE, Brown MB, Wantman E, Kalra SK, Luke B.Live birth rates and birth outcomes by diagnosis using linked cycles from the SART CORS database. J Assist Reprod Genet 2013; 30:1445-50. [PubMed] [CrossRef]

23. Hayashi M, Nakai A, Satoh S, Matsuda Y. Adverse obstetric and perinatal outcomes of singleton pregnancies may be related to maternal factors associated with infertility rather than the type of assisted reproductive technology procedure used. Fertil Steril 2012;98:922-8. [PubMed] [CrossRef]

24. Declercq E, Luke B, Belanoff C, Cabral H, Diop H, Gopal $\mathrm{D}$, et al. Perinatal outcomes associated with assisted reproductive technology: the Massachusetts Outcomes Study of Assisted Reproductive Technologies (MOSART). Fertil Steril 2015;103:88-95. [PubMed] [CrossRef]

25. Berntsen S, Söderström-Anttila V, Wennerholm U-B, Laivuori H, Loft A, Oldereid NB, et al. The health of children conceived by ART: 'the chicken or the egg?' Hum Reprod Update 2019;25:137-58. [PubMed] [CrossRef]

26. Pinborg A, Wennerholm UB, Romundstad LB, Loft A, Aittomaki K, Söderström-Anttila V, et al. Why do singletons conceived after assisted reproduction technology have adverse 
perinatal outcome? Systematic review and meta-analysis. Hum Reprod Update 2013;19:87-104. [PubMed] [CrossRef]

27. Luke B, Gopal D, Cabral H, Diop H, Stern JE. Perinatal outcomes of singleton siblings: the effects of changing maternal fertility status. J Assist Reprod Genet 2016;33:1203-13. [PubMed] [CrossRef]

28. Woo I, Hindoyan R, Landay M, Ho J, Ingles SA, McGinnis LK, et al. Perinatal outcomes after natural conception versus in vitro fertilization (IVF) in gestational surrogates: a model to evaluate IVF treatment versus maternal effects. Fertil Steril 2017;108:993-8. [PubMed] [CrossRef]
29. Kaser DJ, Bormann CL, Myers DE, Missmer SA, Walsh BW, Racowsky C, et al. Cryopreserved embryo transfer is an independent risk factor for placenta accreta. Fertil Steril 2015;103:1176-84. e2. [PubMed] [CrossRef]

30. Palomba S, de Wilde MA, Falbo A, Koster MPH, La Sala GB, Fauser BCJM. Pregnancy complications in women with polycystic ovary syndrome. Hum Reprod Update 2015;21: 575-92. [PubMed] [CrossRef]

31. Lessey BA, Kim JJ. Endometrial receptivity in the eutopic endometrium of women with endometriosis: it is affected, and let me show you why. Fertil Steril 2017;108:19-27. [PubMed] [CrossRef]

This work is licensed under the Creative Commons Attribution-NonCommercial-NoDerivs 4.0 Unported (CC BY-NC-ND4.0) License. To view a copy of this license, visit http://creativecommons.org/licenses/by-nc-nd/4.0/ or send a letter to Creative Commons, PO Box 1866, Mountain View, CA 94042, USA.

Publisher's Note: The content of this publication does not necessarily reflect the views or policies of the publisher, nor does any mention of trade names, commercial products, or organizations imply endorsement by the publisher. Scientific and legal responsibilities of published manuscript belong to their author(s). The publisher remains neutral with regard to jurisdictional claims in published maps and institutional affiliations. 